\title{
Identidad moral y justicia en personas con compromisos sociales y morales extraordinarios
}

\author{
Moral identity and justice among community leaders \\ with extraordinary social and moral commitments
}

Susana Frisancho Hidalgo ${ }^{1}$

Oscar Pain Lecaros ${ }^{2}$

\section{Resumen}

Esta investigación explora el concepto de justicia y las características de la identidad de tres personas fuertemente comprometidas con fines éticos y pro-sociales. Este trabajo es parte de una investigación mayor que exploró, mediante entrevistas, las características del funcionamiento psicológico y las trayectorias de socialización de personas con altos compromisos sociales. Sobre la justicia, los participantes muestran construcciones complejas que integran la equidad y reciprocidad, siendo capaces tanto de contextualizar la justicia a situaciones concretas como de priorizarla por sobre lo legal. Respecto a la identidad, todos han incorporado elementos éticos en ella y un sentido de obligación para hacer lo que hacen. Los resultados se discuten desde la psicología del desarrollo y se analizan sus posibles vinculaciones educativas.

Palabras clave: identidad moral, compromiso moral, juicio moral, ejemplos morales.

1 Pontificia Universidad Católica del Perú. Departamento de Psicología (autor principal).

Lima, Perú. E-mail: sfrisan@pucp.edu.pe

2 Pontificia Universidad Católica del Perú. Departamento de Psicología. Lima, Perú. E-mail: opain@ pucp.pe 


\begin{abstract}
This investigation explores the concept of justice and the formation of identity in individuals with strong social commitments. This work is part of a broader research effort that probed, using interviews, the psychological functioning and socialization patterns among individuals with high levels of social commitment. Concerning justice, the participants articulate complex notions of fairness and reciprocity, and are able both to contextualize their idea of justice in the concrete situations they face and to prioritize justice over legality. We further note that these individuals have incorporated ethical elements into their identity and evince a sense of personal duty behind their actions. These findings are discussed from the standpoint of developmental psychology, and their possible implications for education are also explored.
\end{abstract}

Key words: moral identity, moral commitment, moral judgment, moral exemplars.

En más de una ocasión se ha dicho que cada época, con sus particulares características y contextos, determina las condiciones políticas, económicas, culturales y sociales en las que viven las personas. Esto crea modos idiosincráticos de funcionamiento psicológico que se asocian a las diferentes formas de organización social. Desde esta perspectiva, se ha señalado repetidas veces que el momento en que vivimos es generador de cierto tipo de patología, una personalidad marcadamente narcisista que crea personas centradas en sí mismas, en su cuerpo y en sus propias gratificaciones y placeres, personas altamente individualistas, desvinculadas de lo colectivo y lo público, sin lazos comunitarios, desinteresadas de los temas trascendentes y en las que predomina una razón instrumental que mide el éxito exclusivamente en términos de eficiencia y de valor económico (Martin, 2006; Sandel, 2012; Taylor, 1991).

En efecto, muchos autores han hecho énfasis en la orientación hacia el consumo que trae la época posmoderna, el voraz apetito por tener, por poseer no solamente objetos materiales sino también experiencias y sensaciones. Es lo que Žižek (1999) denomina "el imperativo a disfrutar", 
el llamado a hacer no lo que se debe, sino lo que se quiere y se puede. Como afirma Žižek, la lógica kantiana que indicaba un "puedes hacerlo, porque debes hacerlo" parece haberse invertido hasta llegar a un "debes hacerlo, porque puedes hacerlo". Si es posible (y cada vez más cosas son posibles gracias a los avances de la ciencia y la técnica) entonces debe hacerse, y uno debería sentirse culpable por no aprovechar la posibilidad.

En este panorama, y contrariamente a lo que hemos descrito como personalidad posmoderna líneas arriba, existen también personas que funcionan con otras valoraciones y otros sentidos de vida, seres humanos profundamente interesados en el otro y su bienestar, al que parecen poner incluso por encima de sus propias necesidades y deseos. Dado que personas como estas no son comunes y que el contexto social en el que viven no promueve sus particulares valoraciones y forma de vida, sino todo lo contrario, interesa saber qué experiencias y qué procesos personales hacen que, a pesar de vivir en sociedades orientadas a la búsqueda del placer individual, algunas personas funcionen en términos de lo que vamos a llamar agencia moral (el "puedes hacerlo, porque debes hacerlo" kantiano); en lugar de hacerlo solamente por el temor al castigo o por el afán de gratificarse mediante el consumo y/o la satisfacción de sus deseos y placeres.

En este artículo presentamos parte de un estudio realizado en el Perú con personas que tienen compromisos sociales extraordinarios. Mediante entrevistas cualitativas, se han explorado los patrones de desarrollo y las experiencias de vida significativas de estas personas con el objetivo de: contribuir a explicar los modos y razones por las que desarrollan un sólido compromiso moral hacia la gente y las organizaciones sociales; identificar las características de su identidad y sus nociones de justicia; y, eventualmente, ofrecer pistas a la educación para ayudar a que los niños y jóvenes incorporen características morales en su sentido de sí mismos y se desarrollen de manera más plena. Es importante resaltar que esta investigación es novedosa en el Perú, pues los estudios sobre ejemplos morales se han realizado fundamentalmente en Estados Unidos y Europa, siendo igualmente escasas en esas realidades debido a que las personas con compromisos morales extraordinarios son, por definición, muy poco comunes. En 
general, en Latinoamérica el trabajo en esta línea particular del campo de la psicología moral solo se ha realizado, hasta donde se tiene conocimiento, en Venezuela (ver Farías, 2008; Farías \& Perdomo, 2004).

\section{Antecedentes teóricos}

\section{Identidad moral y ejemplos morales}

La identidad expresa el concepto subjetivo que un individuo tiene de sí mismo (Vignoles, Regalia, Manzi, Golledge \& Scabini, 2006). Se trata de una construcción enraizada en la interacción social y la membresía de grupo, pues la mente y la cultura se van construyendo dinámicamente (Cole, 1995, 1999), siguiendo el tipo de mediación ya señalada por Vygotsky (1978), para quien la interacción y otras formas de actividad humana son mediadas por instrumentos y signos desarrollados en contextos histórico-culturales. Así, las variantes en el desarrollo cultural también implican variaciones en el pensamiento, en las trayectorias de socialización y en las preferencias y valoraciones de las personas.

Un aspecto poco comprendido de la identidad de las personas es la identidad moral, que es el área de la identidad general que incorpora los ideales morales o el sentido ético de la persona, área vinculada a lo que De Ruyter y Conroy (2002) llaman identidad ideal. Esto es, las aspiraciones e ideales que la persona desea alcanzar para guiar su vida, y la perspectiva ética integrada en estos ideales. El concepto de identidad moral proviene de Blasi (1983, 1984, 1993, 1999, 2005; Blasi \& Glodis, 1995) y se asocia al aspecto subjetivo de la identidad, al que William James (1890, 1892) llamó self subjetivo o " $I$ ". Es este aspecto el que permite mantener la continuidad en nuestras experiencias y experimentar sentimientos internos de agrado o desagrado por ser quienes somos. El concepto de identidad moral es importante, porque permite explicar la relación entre el razonamiento moral y la conducta moral, ayudando así a comprender la frecuente discrepancia entre lo que las personas dicen o piensan y aquello que hacen. Al ser la construcción de la identidad moral una empresa fundamentalmente ra- 
cional (Blasi \& Glodis, 1995; Higgins-D’Alessandro \& Power, 2005), una identidad moral sólida produce la necesidad psicológica de comportarse en coherencia con los principios e ideales, ya que de esta manera se evita la inconsistencia, la que a estas personas les genera un malestar psicológico profundo. Al haber integrado estándares éticos dentro de su identidad, para personas con identidades morales fuertes la incoherencia entre lo que piensan y lo que hacen no es solamente una violación de normas externas, sino también una traición a la propia identidad, es decir, al sentido más profundo de lo que son como seres humanos.

Un área de investigación que ha cobrado fuerza en los últimos años es la que explora la configuración de las identidades de personas que tienen extraordinarios compromisos morales y gran coherencia entre su razonamiento moral (aquello que piensan y creen) y su acción moral (aquello que hacen), las que reciben el nombre de ejemplos morales. Ya en 1992, Colby y Damon estudiaron una muestra de veintitrés personas que habían sido identificadas como poseedoras de compromisos morales extraordinarios, los que se evidenciaban en su dedicación a trabajar en beneficio de los demás y en sus acciones éticas. Este estudio fue significativo, porque trajo a la conciencia colectiva de los investigadores el concepto de personalidad moral, que de alguna manera puede entenderse como una reconceptualización moderna de los conceptos "carácter" y "virtud", ya trabajados incluso por Aristóteles.

Un ejemplo moral es una persona que mantiene un compromiso de vida sostenido con ideales éticos y morales, tiene disposición a actuar de acuerdo con estos ideales, así como voluntad de posponer los propios intereses por el bien de los mismos. Además, los ejemplos morales inspiran a otros al mostrarles una perspectiva ética de la vida, poseen un marcado sentido de humildad y muestran mayor integración entre el self y los aspectos éticos o morales de su experiencia (Colby \& Damon, 1992; Matsuba \& Walker, 2005).

La investigación indica también que los ejemplos morales tienen ciertas características distintivas si son comparados con personas promedio. Por ejemplo, Matsuba y Walker (2005) encontraron que, en contraste 
con individuos de un grupo de comparación, los ejemplos morales tenían mayor agradabilidad (tendencia a ser compasivo y cooperativo según el modelo de los cinco grandes factores de personalidad), mostraban una fe más madura, tenían un razonamiento moral más sólido, poseían un mayor sentido de agencia, tenían mayor conciencia del sufrimiento de los otros, habían desarrollado mayor claridad respecto a sus metas futuras y exhibían mayor inclinación a construir relaciones de intimidad. Estas personas logran, además, superar creativamente la tensión existente entre su sentido de agencia como individuos y sus lazos comunitarios, integrando adaptativamente estos dos motivos en su personalidad, lo que los hace ser muy persistentes en llevar a cabo acciones morales y prosociales (Frimer $\&$ Walker, 2009; Frimer, Walker, Dunlop, Lee \& Riches, 2011). Igualmente, Hart y Fegley (1995) encontraron que, en comparación con jóvenes comunes, los adolescentes considerados ejemplos morales eran más propensos a incluir metas morales en la descripción de sí mismos, mostraban mayor sentido de continuidad entre su pasado y su futuro, se pensaban a sí mismos incorporando ideales e imágenes parentales y articulaban una teoría del selfen la que las creencias personales y la filosofía de vida tenían un lugar muy relevante, lo que puede entenderse como un sentido de propósito establecido para sus vidas (Damon, Menon \& Cotton Bronk, 2003).

Obviamente, resulta difícil identificar un único modelo de ejemplo moral, ya que existen opiniones divergentes respecto a lo que significa ser moral -a pesar de que la filosofía ha desarrollado criterios que pretenden alcanzar algún consenso o universalidad- así como diferentes orígenes y rutas de desarrollo de la experiencia moral. Además, como en la práctica ninguna persona es un paradigma intachable de acción que se comporta éticamente todo el tiempo (Walker \& Frimer, 2007; Walker, Frimer $\&$ Dunlop, 2010), la literatura reporta variaciones en el comportamiento moral e indica que no existe un único y uniforme tipo de ejemplo moral. Así, Walker y Frimer (2007) hacen una diferencia entre ejemplos morales "valerosos" que realizan acciones que muestran un valor extraordinario como salvar a alguien en peligro, y ejemplos morales "cuidadores" que muestran un compromiso sistemático por alguna causa social que implique una búsqueda de bienestar y/o de justicia para las personas. Asumien- 
do esta diferenciación, para este estudio seleccionamos solamente participantes que cumplen con las características del ejemplo moral "cuidador".

\section{Justicia, moral y convención}

Kohlberg (1963/2008) planteó que en el curso del desarrollo se van alcanzando modos más maduros de pensamiento moral (los estadios 4 al 6 en su teoría), los que se incrementan entre los 10 y los 16 años a la par que decrecen los modos menos maduros de pensamiento (estadios 1 y 2). Esto implica que las personas pasan de un nivel preconvencional o anterior al sistema legal a uno convencional en el que lo justo se juzga en función de la relación con la tradición, la norma y la costumbre, y luego, en los estadios 5 y 6 , alcanzan una perspectiva moral que informa sus juicios sobre lo justo o injusto de las experiencias humanas.

Turiel $(1983,2002)$ y Nucci $(1982,1996$; Nucci \& Santiago 1982; Nucci \& Turiel, 1978) cuestionan a Kohlberg por señalar que solo en los estadios más altos la moralidad (fairness) se distingue de la convención como base para los juicios morales, y plantean que moralidad y convención se diferencian en estadios más tempranos del desarrollo y constituyen diferentes sistemas conceptuales y evolutivos. Desde esta perspectiva, ya los niños pequeños pueden diferenciar entre trasgresiones morales y trasgresiones a las convenciones, y evalúan las primeras más negativamente que las segundas, aun sin la presencia de regulaciones o normas. Aunque intuitivamente, los nińos parecen comprender que los asuntos morales no son arbitrarios ni están determinados por hábitos o costumbres culturales o por el consenso social al interior de un grupo, sino por factores inherentes a las relaciones sociales como evitar dañar al otro y ofrecer un trato justo para todos, los que son diferentes de las estructuras culturales, religiosas o sociales particulares. Es importante señalar que esta diferenciación entre lo moral y lo convencional ya fue señalada por Kant (1785/1980) en el siglo XVIII al distinguir entre juicios convencionales (imperativos hipotéticos particulares y contingentes) y juicios morales (el imperativo categórico con pretensión universal). 
Siguiendo a Kohlberg, a Turiel, Nucci o al propio Kant, la idea es que moralidad y convención son dominios distintos que las personas logran diferenciar en algún momento de sus vidas. Sin embargo, existen investigaciones que indican que esta diferenciación resulta difícil para muchas personas, incluso para aquellas que ciertamente deberían haber reflexionado sobre estos temas, porque tienen formación filosófica o jurídica y se dedican a impartir justicia o a la educación moral y ciudadana. En una investigación que explora la capacidad de diferenciar moralidad de convención de jueces de la ciudad de Lima, Frisancho (2008) encuentra que muchos tienen dificultades para distinguir el dominio de las convenciones del dominio moral, lo que corrobora la idea que los abogados egresan de las facultades de Derecho con habilidades para el razonamiento legal, pero con poca capacidad para razonar sobre asuntos morales complejos (Mangan, 2007). Otros estudios (Frisancho, 2006; Frisancho \& Ordinola, 2010), esta vez con docentes de educación básica, muestran las dificultades que estos tienen para describirse a sí mismos con categorías morales -lo que evidencia una identidad moral inexistente o poco desarrollada- y para diferenciar moral de convención en relación a la disciplina escolar y al comportamiento de los niños en la escuela.

\section{Método}

Esta es una investigación cualitativa orientada a alcanzar una explicación general en base a las experiencias de los entrevistados. Las entrevistas, realizadas individualmente, fueron grabadas, obteniéndose de cada uno de los participantes el permiso para hacer público sus nombres. Las entrevistas se analizaron para identificar las características de las nociones de justicia y de las identidades morales de cada participante. Estas fueron revisadas por tres codificadores para fortalecer la confiabilidad del análisis, y las discrepancias se discutieron hasta llegar a acuerdos. En un caso la entrevista completa fue revisada por el propio participante, como una forma de verificación de los sentidos de la misma, y en dos casos la información de la entrevista se completó con declaraciones de los participantes en otros medios, como la prensa, o sus propios blogs. Una vez identificadas las 
características más importantes de la noción de justicia y de la identidad moral, se procedió a identificar y posteriormente explicar las relaciones entre ellas (Creswell, 2008; Hernández, Fernández \& Baptista, 2010).

\section{Participantes}

En este artículo se reportan resultados parciales de un proyecto de investigación que incluye a seis participantes, tres hombres y tres mujeres, y que explora sus trayectorias de vida, los procesos psicológicos que soportan su acción, y la construcción de sus identidades. En este texto solo presentamos las nociones de justicia y las características de las identidades de los tres participantes de sexo masculino, los que fueron identificados por su trayectoria como ciudadanos comprometidos, en el discurso y en la acción, con una meta social que los trascendía como individuos.

Se elaboró un listado de criterios de selección para los participantes a partir de lo que plantea la literatura especializada y en base al conocimiento que de ellos tenían los investigadores, quienes los reconocían como agentes de cambio social y personas con amplia trayectoria de compromiso por el bienestar y los derechos de los otros. De este modo, los participantes fueron seleccionados tomando en cuenta que: tuvieran un fuerte compromiso social que involucre tiempo (trabajo prolongado por más de diez años) de dedicación a una o varias causas (prosociales/altruistas), de las cuales la mayor parte no son remuneradas; contaran con reconocimiento social en su comunidad o en las que realizan su trabajo; tuvieran cierta presencia en los medios, ya sea porque estos reportan su trabajo o porque la misma persona usa los medios como apoyo a su labor; y finalmente, su trayectoria fuera reconocida y apreciada por los investigadores.

El primero, Alcides Silva, tiene 59 años al momento de la entrevista y es natural de Cajamarca, departamento de la sierra norte del Perú, aunque reside en Trujillo, ciudad de la costa norte peruana, desde que a los diez años escapó de su casa. Estudió la primaria con normalidad en una escuela pública, pero la secundaria la terminó de adulto con clases nocturnas. Alcides trabajó durante su infancia vendiendo periódicos, arre- 
glando plátanos en el mercado o como muchacho de mandados, pues no tenía familia ni recursos económicos. Al momento de la entrevista, Alcides trabajaba en una empresa privada de almacenaje como administrador y encargado general de las operaciones, aunque no tiene estudios superiores en el área. De manera voluntaria, participa de varios movimientos de agricultores arroceros de las ciudades de Chepén y Jequetepeque, a los que ayuda a organizarse y a defender sus derechos, y forma parte de diversas asociaciones recreativas y con fines sociales. Actualmente estudia Derecho con la finalidad de "entender mejor la justicia" y porque piensa que "es muy triste que se siente una persona frente a un juez, cuando es inocente".

El segundo participante es José Ignacio Mantecón, conocido como "Chiqui", un sacerdote jesuita de 63 ańos nacido en Zaragoza, España, nacionalizado peruano y que reside en el Perú desde hace más de 30 años, "porque mi vida está aquí". Chiqui, cuya familia de origen tenía una buena posición social, realizó sus estudios básicos y superiores y su formación teológica en España. La educación básica, que hizo en un colegio jesuita, le "abrió la mente" y lo puso en contacto con el mundo de los pobres. En el Perú vive en el distrito de El Agustino, una de las zonas más peligrosas de Lima, donde desde un inicio estuvo "cerca de la muerte" y de muchas experiencias extremas que lo llevaron a trabajar por la reducción de la violencia y la reinserción social de jóvenes delincuentes, pues, como afirma, "trabajo por la dignidad de los jóvenes, por hacer que se entienda que todos tenemos dignidad, incluso los que están al margen de este mundo".

El tercer participante es Wilfredo Ardito, un abogado de 45 años, natural de Lima, proveniente de una familia de clase media. Wilfredo realizó sus estudios primarios y secundarios en un colegio privado de la capital, estudió Derecho en una reconocida universidad privada, hizo una maestría en Derecho Internacional en Inglaterra y un doctorado en el mismo tema. Ha trabajado en organismos no gubernamentales desde fines de los años ochenta, haciendo capacitación, investigación, preparando propuestas de ley y escribiendo artículos. Se considera un activista social, una persona movida a actuar por "una vocación o una sensación que yo sentía que con mi tiempo tenía que hacer algo", por la idea de comprometerse para generar 
un cambio en la sociedad y por una necesidad de responder a la injusticia. "¿Yo qué voy a hacer frente a todo ese tipo de pobreza, injusticia y todo lo que veo?”, se preguntaba frecuentemente. Como abogado, Wilfredo se dedica a temas de derechos humanos, racismo y discriminación. Ha sido integrante de la Asociación Pro Derechos Humanos [APRODEH] y del Instituto de Defensa Legal [IDL].

\section{Instrumento}

Se elaboró una entrevista semiestructurada en base a la propuesta de Colby y Damon (1992), la que se adaptó a partir de la revisión de la literatura. Los temas de la entrevista fueron agrupados en las seis siguientes áreas: historia de vida, enfocada en las experiencias y acontecimientos que el entrevistado consideró como más importantes a lo largo de su vida; fuentes o precursores de su interés social, los distintos modelos de vida que considera relevantes, sus motivaciones para el estudio, el trabajo y los sistemas de creencias, políticos o religiosos, que profesa o experimentó en algún momento; percepciones sociales sobre los otros y de los otros sobre sí mismo; identidad moral; nociones de justicia; y, finalmente, los costos personales y sociales percibidos, producto de su compromiso social.

Asimismo, dada la flexibilidad de la entrevista semiestructurada, se profundizó también de manera transversal en: el proceso de socialización durante la infancia y adolescencia; el proceso de socialización durante la adultez; los procesos de construcción de la identidad moral; y eventos de vida que hayan tenido un impacto en sus principios y en la manera en que dan sentido a su vida.

\section{Resultados}

\section{Identidad moral}

Es interesante encontrar que respecto a cómo se definen como persona, los tres participantes manifiestan sentirse esencialmente "buenas personas". Esto indica que todos han construido una visión de sí mismos 
que integra características morales y un sentido último de bondad. Para ellos, ser una buena persona significa vincular su propia existencia con la de los demás, reconocerlos como seres humanos con alegrías y sufrimientos, ser lo suficientemente sensible a sus experiencias, poder identificarse con ellas y, además, tener algún compromiso con la mejora de sus vidas, hacer algo, como dice Alcides, "para que otros menos sufrieran”. Una afirmación de Chiqui ilustra estos puntos y es una muestra de lo que declaran los tres participantes:

Yo creo que soy una persona fundamentalmente... buena, en el buen sentido de la palabra. Ah... no muy rebuscada, que sintonizo muy bien con las alegrías y con las tristezas de la gente que me rodea... que siento, y por eso tal vez no me cuesta nada, que es natural que tengamos que estar a disposición de los que tienen menos que nosotros, no solo a nivel económico, sino de muchas cosas. Yo soy un... una buena persona. No más. (Chiqui. Entrevista personal. 20 jul. 2010).

Es importante señalar que, siguiendo lo que reporta la literatura, también en los tres participantes se nota un sentido personal de "obligatoriedad", una manera de entender su vida y sus acciones como necesarias, es decir, como el único camino posible para actuar y transitar por la vida. El "no me cuesta nada" de Chiqui ilustra bien esta experiencia. En este sentido, ninguno de ellos considera sus acciones como extraordinarias, sino solo como la única opción de vivir sus vidas con dignidad y sentido. Si bien los tres reconocen que las cosas que hacen "no son comunes", y que esto entraña esfuerzo y renuncias, su percepción general es que se trata simplemente del único modo de hacer las cosas. Muchas veces, tal como Wilfredo afirma en la entrevista, actuar como actúan "está tan internalizado que ni me doy cuenta”. Esto parece ser una característica de los ejemplos morales ya identificada por Colby y Damon (1992) como un sentido de humildad, la percepción de que lo que hacen es simple, lo único que podrían hacer, algo que no merece reconocimiento. $\mathrm{Al}$ recordar su experiencia en un microbús, Wilfredo dice: 
Por ejemplo, yo hablo con el cobrador de combi [microbús de 15 pasajeros de transporte público], una vez el cobrador de combi me dice “isi todos los pasajeros fueran como usted...!” porque lo había tratado bien. Y a veces me lo dicen un montón, pero ¡no he hecho nada! Me impresiona que lo que uno considera normal a otros les llame la atención. O sea, tratar al otro como una persona, ¿no? (Wilfredo. Entrevista personal. 3 mayo 2011).

En los tres participantes se ha encontrado también un nivel avanzado de autoconciencia, pues pueden dar cuenta de sus procesos internos, de sus valoraciones, de los incidentes que han sido influyentes en sus vidas, las regularidades en cuanto a intereses y preocupaciones, así como de los cambios en la visión del mundo por los que han atravesado. Siguiendo a Piaget (1974/1981), la toma de conciencia comprende la transferencia de elementos de un plano inferior usualmente inconsciente y/o automático, a un plano superior y consciente en el cual se reconstruyen. Se trata de lograr una conceptualización, el paso de la acción a la representación por un proceso que reconstruye y luego sobrepasa, en el plano de semiotización, lo que se había adquirido en el de los esquemas de acción. Por ejemplo, Wilfredo es consciente de que hay consistencias temáticas respecto a asuntos, como el racismo, "que me tenía marcado desde niño" y sobre los cuales ha ido desarrollando y complejizando una postura ética. A la vez, es también plenamente consciente de que su manera de pensar respecto a varios temas de importancia ha cambiado a lo largo de su vida:

Para mí, la moral tiene relación con la buena conducta de una persona. La orientación sexual no tiene mayor relevancia en ello, como tampoco la tienen el estado civil, la estatura o el lugar de origen, aunque debo admitir que hace veinte años yo no pensaba de esta manera (Wilfredo. Entrevista personal. 3 mayo 2011).

La literatura indica que una característica importante de los ejemplos morales es la fuerte necesidad de mantener la integridad personal, 
entendida esta como la necesidad psicológica de hacer que las acciones sean coherentes con los principios e ideales que la persona ha construido y mantiene para su vida (Blasi, 1984, 2005). Ya Kohlberg y Diessner (1991) plantearon que la disposición moral central que resulta de una identidad moral sólida es un sentido de responsabilidad que conlleva una necesidad de actuar en términos de los juicios y estándares morales que la persona ha desarrollado, la capacidad de sentir culpa o vergüenza por trasgredir dichos estándares y de sentir aprecio por realizarlos. En otras palabras, de una identidad moral sólida se deriva la necesidad de establecer consistencia entre acción y pensamiento, pues la consistencia personal se convierte en fuerza motivacional para la acción moral. Esta motivación suele estar tan integrada en la persona, que esta persiste en su tarea aun cuando hacerlo sea difícil, tenga un costo personal y/o las condiciones sociales externas no sean favorables. En el caso de nuestros tres participantes esta característica es evidente también, siendo la necesidad de tener coherencia personal una motivación importante para sus vidas, motivo que solo puede satisfacerse mediante la congruencia entre el juicio y la acción. Wilfredo ejemplifica esto al declarar: "yo pienso que por encima de todo hay que mantener la coherencia entre lo que tú piensas y lo que haces, ¿̨no? Independientemente de que el mundo que te rodea no sea el ideal".

Como puede observarse, la identidad dirige la percepción, la memoria y las inferencias concernientes a uno mismo y los otros, y es también una fuente de agencia y voluntad, pues regula el comportamiento intencional y permite a la persona funcionar en su mundo social. El sentir la necesidad de establecer consistencia entre acción y pensamiento es un logro tardío del desarrollo, basado en la aceptación de responsabilidad por las propias acciones y en la definición que se hace de uno mismo integrando categorías morales.

\section{Dominios sociales: justicia y convención}

La búsqueda de justicia aparece como el motor detrás de las acciones de los tres entrevistados. Esta se entiende, como afirma Chiqui, 
como "el respeto de la persona humana por encima de todo"; la ausencia de desigualdades, en palabras de Wilfredo, que "todos los habitantes de una sociedad tengan las mismas oportunidades y posibilidades". Los tres reconocen que la religión no es el único modo de llevar una vida con sentido, pero consideran que su experiencia religiosa los ayuda a mantener el compromiso y permite de mejor manera que sus principios y sus acciones guarden coherencia. Resulta importante destacar que los tres participantes vinculan su visión de la justicia con su modo particular de vivir la fe. Chiqui afirma que, desde su fe, la justicia es "lo del mito, el relato del génesis. Un paraíso que Dios vio que era muy bueno y una humanidad puesta ahí para construir la felicidad"; mientras que Wilfredo encuentra su principal motivación para trabajar por la justicia en su manera de concebir a Dios como un Dios de amor. Alcides, por su parte, encuentra en Dios su paradigma de justicia, pues "Dios para mí es justo... saca el sol para todos, para buenos y malos... para todos". La justicia para ellos funciona así como un factor motivacional y muestra múltiples facetas: incluye un concepto de igualdad pero también una visión de la equidad, así como la integración de factores afectivos, usualmente no asociados con el concepto de justicia, ligados al bienestar, la realización humana, la evitación del sufrimiento y la consecución de la felicidad.

Sobre la relación entre justicia y convenciones sociales, en los tres casos se reconoce, con plena conciencia, la posibilidad de pasar por encima de la norma cuando la situación encierra una perspectiva moral y/o atenta contra el bienestar o los derechos de las personas. Esto evidencia una clara diferenciación entre lo cultural y lo moral; frente a un conflicto siempre se privilegia lo segundo por sobre lo primero, pues, como indican todos, "por encima de las leyes están las personas". Por ejemplo, en relación al seguimiento de la ley y su relación con la dignidad de las personas, Chiqui dice:

No tanto que la ley es un absurdo, porque hay muchísimas leyes absurdas $y$, sin embargo... pues si quieres que la sociedad funcione tienes que mantenerte, ¿no? Pero si esas leyes absurdas van contra la dignidad de la persona, entonces no, la persona es más importante (Chiqui. Entrevista personal. 22 jul. 2010). 
Y más adelante añade:

Si yo pienso que tengo, y ahí viene el problema, que tengo una responsabilidad, pues si la Iglesia me dice que no, pues les diría que lo siento. La gente está antes que la Iglesia. La Iglesia no es un absoluto, ni la Compañía de Jesús, ni la familia.... yo creo que no es un absoluto que tiene que condicionar todo. Para mí lo que tiene que condicionar mi vida es la gente a la que yo me debo (Chiqui. Entrevista personal. 22 jul. 2010).

Alcides va también en esta línea. Respecto a su motivación para estudiar Derecho y a su visión de lo legal en relación con la justicia, explica:

Sí, recién con motivo de este estudio que estoy llevando ¿no?, como ya estoy en los últimos ciclos, entonces, me he dado cuenta de que es necesario que nos juntemos. A los amigos de mi promoción les he conversado y están resueltos a defender lo que nosotros conocemos, la ética del derecho, en la búsqueda de la justicia. No solo apegarme a la ley. A lo mejor esa ley está mal dada para el pueblo. Uno tiene que luchar por la justicia, la búsqueda de la justicia, incluso ir en contra de ese derecho que no está acorde de las necesidades del pueblo, de la sociedad (Alcides. Entrevista personal. 20 ago. 2011).

Esto también ocurre respecto a la relación entre prácticas culturales y morales, observándose que los participantes tienen una perspectiva mayor para el análisis de las primeras, que supedita lo cultural a lo moral. Esto significa que aunque se valoran las tradiciones, estas se cuestionan cuando atentan contra algún derecho fundamental. Por ejemplo, Wilfredo afirma en su blog:

Yo creo que la cultura tiene que respetar unos mínimos morales. Por ejemplo, sería inadmisible una película o una obra teatral que glorificara a Hitler o a Abimael Guzmán [Líder del grupo 
terrorista Sendero Luminoso], que promoviera el racismo o el machismo. Para mí no puede haber ninguna justificación cultural para prácticas tan brutales como el charaje o el takanakuy y tampoco para las peleas de gallos o las corridas de toros (Wilfredo, 23 ago. 2011).

Las prácticas culturales más terribles existentes en el Perú son el takanakuy o el charaje, que se realizan en las provincias cusqueñas de Chumbivilcas y Canas, respectivamente. En ambos casos, comunidades enteras se atacan con piedras o a golpes en una sanguinaria batalla ritual, que frecuentemente deja muertos, discapacitados o heridos graves. Y, por supuesto, las campesinas pobres terminan siendo también víctimas, porque deben mantener a sus hijos y al marido lisiado.

[...] ¿Debemos resignarnos a que subsistan las costumbres que afectan la vida humana, que generan daños irreparables en la salud o que atentan contra el medio ambiente? En mi opinión, sería un fatalismo inaceptable. En toda sociedad, las costumbres cambian, por diversos factores. Las mujeres ahora desarrollan trabajos que antes no les eran permitidos. Muchos limeños se están habituando a pagar a las trabajadoras del hogar lo que manda la ley. Inclusive los indígenas amazónicos han cambiado muchas costumbres. Hace medio siglo, por ejemplo, los shipibos celebraban el Ani Sheati, una gran fiesta con motivo de la extirpación del clítoris de las adolescentes. Ahora esta práctica, afortunadamente, es solo un recuerdo (Wilfredo, 21 feb. 2010).

Finalmente, aunque aprecian las convenciones y las siguen cuando resulta necesario, en su vida cotidiana también pueden relativizarlas y ponerlas en una perspectiva mayor que les dé un marco más amplio de sentido. En relación a su propia vestimenta como sacerdote, Chiqui, que maneja moto, canta rock, no usa ninguna indumentaria especial y lleva un arete pequeño en una oreja, dice en una entrevista previa: 
Y aún no has visto mi tatuaje de Martin Luther King. No sé por qué el sacerdote debe tener un atuendo especial. Yo vengo de la generación de Woodstock, y eso marca. No sé si lo haré bien o mal, pero yo creo que me encuentro bien con la gente con la que me muevo -quizá a otros les costaría un poco más-, y creo que incluso las viejecitas de la parroquia me quieren así (Padre Chiqui: "Yo conseguí la primera batería de El Agustino", 2006).

\section{Discusión y conclusiones}

En un contexto como el latinoamericano, que por sus características políticas, culturales y sociales históricas, y actuales, presenta enormes retos para la convivencia democrática y la construcción de sociedades más justas e inclusivas, resulta fundamental entender qué características psicológicas, educativas y sociales han llevado a algunas personas a diferenciarse de las demás, desarrollar altos estándares éticos y buscar el bien común. En un mundo posmoderno que promueve el consumo y la autogratificación y que, se dice, produce no un único self sino múltiples y escindidos selves (Gergen, 1992), hemos encontrado que en estas tres personas existe un self integrado y construido con características morales poco comunes. Esto significa que es posible, dadas determinadas condiciones, crecer y desarrollarse formando identidades con componentes morales sólidos. Como afirma MacIntyre (1984):

The fact that the self has to find its moral identity in and through its membership in communities ... does not entail that the self has to accept the moral limitations of the particularity of those forms of community. Without those moral particularities to begin from there would never be anywhere to begin; but it is in moving forward from such particularity that the search for the good... consists (p. 143) ${ }^{3}$.

\footnotetext{
3 El hecho de que el self debe hallar su identidad moral en y a través de su pertenencia a comunidades... no significa que deba aceptar las limitaciones morales de las particularidades de esas formas de comunidad. Sin esas particularidades morales desde las cuales empezar no habría ningún lugar por el cual comenzar; pero la búsqueda del bien consiste precisamente en moverse más allá de esa particularidad (traducción de los autores).
} 
Aunque se piensa que en la posmodernidad es difícil hablar de un selfintegrado, pues las condiciones de vida plantean a las personas demandas tan diversas que las hacen construir múltiples identidades, Covaleskie (2011) cree que esto es un error debido a la confusión entre identidad y roles. Así, sería cierto que las personas cumplen con múltiples roles en sus vidas diarias, pero esto no necesariamente produciría una identidad fracturada. Al menos en los casos que hemos presentado en este artículo, esta idea resulta sugerente.

¿Podría la investigación con ejemplos morales orientar a la educación, entendida esta en un sentido amplio? Esta pregunta es importante porque coincidimos con De Ruyter y Conroy (2002) cuando señalan que los ideales y su relación con la identidad individual y colectiva no tienen mayor presencia en el escenario educativo. Ya en otro lugar (Frisancho, 2007) se ha planteado que esta ausencia debería enmendarse, puesto que para la educación moral no es suficiente formar la identidad general de los niños y jóvenes. Se requiere, sin duda, ayudarlos a integrar en ella elementos éticos y morales de manera sistemática y explícita y, en este sentido, incluir el aspecto ideal de la identidad resultaría importante para los programas educativos ya que, como este estudio evidencia, los ideales de vida son parte esencial de las identidades morales. Esto implica, para la educación, asumir un telos o dirección del desarrollo hacia la cual orientar a los niños y jóvenes (se puede consultar Cairns, 1998, para mayor información sobre el concepto de dirección de desarrollo).

Del mismo modo, procesos que lleven a los niños a tomar cada vez mayor conciencia sobre sí mismos, su subjetividad, sus valoraciones y sobre la experiencia del otro, resultan fundamentales para la formación de personalidades morales. Es importante proporcionarles también oportunidades para construir una perspectiva realista de sus propias limitaciones, para conocer y hacer lo justo y lo bueno, lo que constituye un aspecto de la virtud de humildad. En este sentido, recurrimos a Jean Piaget (1974/1981) y a Paulo Freire (1970/2003), quienes, cada uno a su manera, señalan la importancia de la toma de conciencia en los procesos educativos. No hay palabra verdadera que no sea unión inquebrantable entre acción y reflexión, decía Freire, y no existe conciencia sin reflexión sobre la acción, 
planteaba Piaget. Llevar a los estudiantes a una mayor conciencia de sí mismos a partir de su propio actuar en el mundo resulta fundamental como meta pedagógica.

Para concluir, queremos destacar que, de un modo u otro, estas tres personas muestran una fe religiosa que juega un papel importante en su vida moral. Chiqui es un sacerdote jesuita con un sentido de fe esencial, Alcides perteneció a varias iglesias y ahora se considera católico, y para Wilfredo la religión fue muy importante en los años ochenta y noventa, durante el conflicto armado interno que vivió el Perú. Como hemos visto al analizar su concepto de justicia, en los tres casos está vinculada a la fe religiosa. En su estudio de 1992, Colby y Damon encontraron también que casi el $80 \%$ de los participantes atribuyó las valoraciones y compromisos subyacentes a sus acciones a su fe religiosa. Es también evidente que existe una conexión entre moral y religión (Keljo \& Christenson, 2003; Walker, 2003) aún poco explorada desde la psicología, a pesar que ya desde William James $(1890,1892)$ se tiene alguna evidencia de que una experiencia religiosa auténtica va de la mano de un funcionamiento moral maduro, el que tendría que ver con una visión espiritual de la vida no necesariamente vinculada a una religión específica pero sí, tal como el mismo Kohlberg propuso, a un sentido trascendente o cósmico de la existencia humana (ver Kohlberg \& Power, 1981). Si bien no consideramos que moral y religión sean necesarias la una para la otra, en un continente tan religioso como el latinoamericano esta es una línea de investigación interesante que debería explorarse más en el futuro.

\section{Referencias}

Ardito, W. (2010, post del 21 de febrero). Las malas costumbres no son eternas. En Reflexiones peruanas. [Blog] Recuperado de http://reflexionesperuanas.lamula.pe

Ardito, W. (2011, post del 23 de agosto). Cultura: dejando el elitismo. En Reflexiones peruanas. [Blog] Recuperado de http://reflexionesperuanas.lamula.pe 
Blasi, A. (1983). Moral cognition and moral action: A theoretical perspective. Developmental Review, 3, 178-210.

Blasi, A. (1984). Moral identity: its role in moral functioning. En W. Kurtines \& J. Gewirtz (Eds.). Morality, moral behavior, and moral development (pp.128-139). New York: John Wiley \& Sons.

Blasi, A. (1993). The development of identity. Some implications of moral functioning. En G. G. Noam \& T. E. Wren (Eds.). The moral self (pp. 99-122). Cambridge: The MIT Press.

Blasi, A. (1999). Emotions and moral motivation. Journal for the Theory of Social Behaviour, 29, 1-19.

Blasi, A. (2005). Moral character: a psychological approach. En D. K. Lapsley. Character psychology and character education (pp. 67-100). Indiana: University of Notre Dame.

Blasi, A. \& Glodis, K. (1995). The development of identity. A critical analysis from the perspective of the self as subject. Developmental Review, 15, 404-433.

Cairns, R. B. (1998). The making of developmental psychology. En W. Damon (Ed.). Handbook of child psychology: The fifth edition, 1, 25106. New York: Wiley.

Cole, M. (1995). Culture and cognitive development: From cross-cultural research to creating systems of cultural mediation. Culture \& Psycho$\log y, 1,25-54$.

Cole, M. (1999). Psicología Cultural. Madrid: Morata.

Covaleskie, J. F. (2011). Integrity and identity: judgment and the moral self. Philosophy of Education, Year 2011, 308-315.

Colby, A. \& Damon, W. (1992). Some do care: contemporary lives of moral commitment. New York: Free Press.

Creswell, J. (2008). Educational research:planning, conducting, andevaluation quantitative and qualitative research. Columbia: Pearson.

Damon, W., Menon, J. \& Cotton Bronk, K. (2003). The development of purpose during adolescence. Applied Developmental Science, 7(3), 119-128.

De Ruyter, D. \& Conroy, J. (2002). The formation of identity: the importance of ideals. Oxford Review of Education, 28(4), 509-522.

Farías, L. (2008). La comunidad en carne propia. Un estudio biográfico del altruismo y la madurez moral en barrios caraqueños. Caracas: Universidad Central de Venezuela.

Farías, L. \& Perdomo, G. (2004). Moral dilemmas of community leaders and sense of community. Journal of Prevention and Intervention in the Community, 27(1), 25-37. 
Freire, P. (1970/2003). Pedagogia do oprimido. Rio de Janeiro: Ediçóes Paz e Terra.

Frimer J. \& Walker. L. (2009). Reconciling the self and morality: An Empirical Model of Moral Centrality Development. Developmental Psychology, 45(6), 1669-1681.

Frimer, J., Walker, L., Dunlop, W., Lee, B. \& Riches, A. (2011). The integration of agency and communion in moral personality: evidence of enlightened self-interest. Journal of Personality and Social Psychology, 101(1), 149-163.

Frisancho, S. (2006). Individualism, communitarianism, and the question of a communal morality in high school teachers. Disertación doctoral no publicada. Universidad de Fordham, New York.

Frisancho, S. (2007). La identidad moral: elemento fundamental para una cultura de los Derechos Humanos. Documentos de trabajo, serie Democracia y Sociedad, No 1 . Lima: IDEHPUCP.

Frisancho, S. (2008). Jueces y corrupción: algunas reflexiones desde la psicología del desarrollo moral. Revista Memoria, 4, 65-72.

Frisancho, S. \& Ordinola, E. (2010). Disciplina Escolar y Formación ciudadana. Una experiencia de acompañamiento e investigación. Ponencia presentada en las X Jornadas de Psicología Educacional, La Serena, Chile, Octubre de 2010.

Gergen, K. (1992). The saturated self: dilemmas of identity in contemporary life. New York: Basic books.

Hart, D. \& Fegley, S. (1995). Prosocial Behavior and Caring in Adolescence: Relations to Self-Understanding and Social Judgment. Child Development, 66(5), 1346-1359.

Hernández, R., Fernández, C. \& Batista, P. (2010). Metodología de la Investigación. México D.F: MacGraw-Hill.

Higgins-D'Alessandro, A. \& Power, C. (2005). Character, Responsibility, and the Moral Self. En D. K. Lapsley \& F. C. Power (Eds.). Character Psychology and Character Education (pp. 101-120). Notre Dame: University of Notre Dame Press.

James, W. (1890). Principles of Psychology. Chicago: Encyclopedia Britannica.

James, W. (1892). Psychology: the brief course. New York: Henry Holt.

Kant, E. (1785/1980). Fundamentación de la metafísica de las costumbres. Madrid: Espasa Calpe.

Keljo, K. \& Christenson, T. (2003). On the relation of morality and religion: two lessons from James's varieties of religious experience. Journal of moral education, 32(4), 385-396. 
Kohlberg, L. (1963/2008). The development of children's orientations toward a moral order. I. Sequence in the development of moral thought. Human development, 5, 8-20. Reimpresión de Vita Humana 1963, 6, 11-33.

Kohlberg, L. \& Power, C. (1981). Moral development, religious thinking, and the question of a seventh stage. Essays on moral development. Vol. I: Philosophy of Moral Development. San Francisco: Harper \& Row.

Kohlberg, L. \& Diessner, R. (1991). A cognitive-developmental approach to moral attachment. En J. L. Gewirtz \& W. M. Kurtines (Eds.). Intersections with Attachment (pp. 229- 246). New Jersey: Erlbaum.

Mangan, K. (2007). Carnegie Foundation report suggests more focus on clients, less on Socratic dialogues. Chronicle of Higher Education, 53(20), A6-A8.

Martin, F. (2006). Cambios sociales y trastornos de la personalidad posmoderna. Papeles del psicólogo, 2(27), 104-115. Recuperado de http:// www.papelesdelpsicologo.es/vernumero.asp? $\mathrm{id}=1342$

Matsuba, M. K. \& Walker, L. (2005). Young adult moral exemplars: the making of self through stories. Journal of research on adolescence, 15(3), 275-297.

Maclntyre, A. (1984). The virtues, the unity of a human life, and the concept of a tradition. En M. J. Sandel (Ed.). Liberalism and its critics (pp. 125-148). New York: New York University Press.

Nucci, L. (1982). Conceptual development in the moral and conventional domains: implications for values education. Review of educational research, 52(1), 93-122.

Nucci, L. (1996). Morality and the personal sphere of actions. En E. Reed, E. Turiel \& T. Brown (Eds.). Values and Knowledge (pp. 41-60). New Jersey: Lawrence Erlbaum Associates.

Nucci, L. \& Santiago, M. (1982). Children's social interactions in the context of moral and conventional transgressions. Child development, 53(2), 403-412.

Nucci, L. \& Turiel, E. (1978). Social interactions and the development of social concepts in preschool children. Child Development, 49, 400407.

Padre Chiqui. Yo consegui la primera batería de El Agustino (2006) Recuperado de http://peru21.pe/impresa/noticia/padre-chiqui-yo-consegui-primera-bateria-agustino/2006-03-06/74762

Piaget, J. (1974/1981). La toma de conciencia. Madrid: Morata.

Sandel, M. (2012). What money can't buy: the moral limits of markets. New York: Farrar, Straus and Giroux. 
Taylor, C. (1991). The ethics of authenticity. Cambridge: Harvard University Press.

Turiel, E. (1983). The development of social knowledge: morality and convention. New York: Cambridge University Press.

Turiel, E. (2002). The culture of morality: social development, context, and conflict. New York: Cambridge University Press.

Vignoles, V., Regalia, C., Manzi, C., Golledge, J. \& Scabini, E. (2006). Beyond self-esteem: influence of multiple motives on identity construction. Journal of personality and social psychology, 90(2), 308-333.

Vygotsky, L. S. (1978). Interaction between learning and development. En M. Cole, V. John-Steiner \& S. Scribner (Eds.). L. S. Vygotsky, mind in society: the development of higher psychological processes (pp. 79-91). London: Harvard University Press.

Walker, L. (2003). Morality, religion, spirituality-the value of saintliness. Journal of moral education, 32(4), 373-384.

Walker, L. \& Frimer, J. (2007). Moral personality of brave and caring exemplars. Journal of personality and social psychology, 93(5), 845860.

Walker, L, Frimer, J. \& Dunlop, L. (2010). Varieties of moral personality: beyond the banality of heroism. Journal of Personality, 78(3), 907942.

Žižek, S. (1999). 'You may!'. London Review of Books, 21(6), 3-6. Recuperado de http://www.lrb.co.uk/v21/n06/slavoj-zizek/you-may

Fecha de recepción: 07 de agosto de 2012.

Fecha de aceptación: 15 de noviembre de 2012. 